\title{
Significance of force transfer in mitral valve-left ventricular interaction: In vivo assessment
}

\author{
Jesper B. Askov, PhD, ${ }^{\mathrm{a}, \mathrm{b}}$ Jesper L. Honge, MD, PhD, ${ }^{\mathrm{a}}$ Morten O. Jensen, PhD, ${ }^{\mathrm{a}, \mathrm{b}}$ Hans Nygaard, DMSc, ${ }^{\mathrm{a}, \mathrm{b}}$ \\ J. Michael Hasenkam, MD, ${ }^{\mathrm{a}}$ and Sten L. Nielsen, $\mathrm{MD}, \mathrm{PhD}^{\mathrm{a}}$
}

\begin{abstract}
Objective: The objective of this study was to assess the combined force transfer from the papillary muscle tips to the mitral valve through the chordae tendineae in vivo, and thereby quantify the force transmitted through the papillary-chordal complex to augment left ventricular ejection.
\end{abstract}

\begin{abstract}
Methods: In an acute porcine model $(\mathrm{n}=8)$, force transfer between papillary muscles and the mitral valve was recorded on the anterior and posterior papillary muscle tip using dedicated force transducers. Ultrasound sonomicrometry was utilized to record and calculate left ventricular long-axis shortening and mitral annular geometry. The closing force acting on the mitral valve leaflets was calculated as mitral annular area multiplied by the transmitral pressure difference throughout systole. Mitral valve competence was verified before measurements with color Doppler ultrasound.
\end{abstract}

Results: Peak force in the anterior and posterior papillary muscle was $5.9 \pm 0.6 \mathrm{~N}$ and $5.8 \pm 0.7 \mathrm{~N}$ (mean \pm standard error of the mean), respectively, and peak closing force was $6.8 \pm 0.3 \mathrm{~N}$ all at a transmitral pressure of $90 \mathrm{~mm} \mathrm{Hg}$. Peak rate of left ventricular contraction coincided with peak papillary muscle force.

Conclusions: This study is the first to assess the magnitude and time course of the longitudinal force transmitted through the papillary-chordal complex to the left ventricular wall during ejection. The study also demonstrates a significant force transfer to the closing force acting on the mitral valve leaflets that constitutes an essential component of valvular-ventricular interaction to enhance left ventricular systolic pump performance. The magnitude of the combined papillary muscle force component emphasizes the crucial role of preserving mitral valve-left ventricular continuity in mitral valve surgery. (J Thorac Cardiovasc Surg 2013;145:1635-41)

\section{Supplemental material is available online.}

Studies suggest that a complex mechanical coupling exists between the mitral valve (MV) and the left ventricular (LV) wall mediated through the papillary muscles (PMs) and the chordae tendineae. ${ }^{1-5}$ This valvular-ventricular interaction has been widely investigated and several studies have shown that severing of the chordae and disconnection of the continuity between the MV and PMs has adverse effects on ventricular performance in terms of

\footnotetext{
From the Department of Cardiothoracic and Vascular Surgery and Institute of Clinical Medicine, ${ }^{\text {a }}$ Aarhus University Hospital, Skejby, Aarhus, Denmark; and the Department of Biomedical Engineering, ${ }^{\mathrm{b}}$ Engineering College of Aarhus, Aarhus, Denmark.

This research was made possible by grants from the Danish Heart Foundation (grant 09-04-R72-A2410-22556), the Snedkermester Sophus Jacobsen og Hustru Astrid Jacobsens Fond, the Arvid Nilssons Fond, and the Korning Fonden.

Disclosures: Authors have nothing to disclose with regard to commercial support.

Received for publication April 20, 2012; revisions received July 10, 2012; accepted for publication July 26, 2012; available ahead of print Sept 13, 2012.

Address for reprints: Sten L. Nielsen, MD, PhD, Department of Cardiothoracic and Vascular Surgery T and Institute of Clinical Medicine, Aarhus University Hospital, Skejby, Brendstrupgaardsvej, 8200 Aarhus N, Denmark, DK (E-mail: lyager@ki. au.dk).

0022-5223/\$36.00

Copyright (C) 2013 by The American Association for Thoracic Surgery

http://dx.doi.org/10.1016/j.jtcvs.2012.07.062
}

its pressure-generating ability, shape, and contractile function. The axis of the PMs is generally oriented in a direction parallel to the axis of the LV cavity, and the shortening of the PMs during LV ejection maintains the distance from the PM tips to the annular plane constant within a few millimeters. ${ }^{6,7}$ The general assumption is that the PMs serve mainly as anchors of the chordae to prevent prolapse of the MV leaflets into the left atrium. These anchoring forces may play a dual role by anchoring the LV wall to support the regional LV systolic wall mechanics as well. The beneficial effect of preserving or resuspending the chordae from the mitral annulus to the PM tips during MV replacement on LV systolic function suggest an additional role of the mechanical coupling between the mitral annulus to the PMs, but the supposed force transfer associated with this mechanism has not yet been quantified in vivo. The aim of this study was to assess the total force transfer at the PM tip between the MV apparatus and the LV wall in vivo to differentiate the closing forces generated by the LV pressure (LVP) acting on the MV leaflets, and the potential forces responsible solely for the valvular support of the LV wall (valvular-ventricular interaction).

\section{METHODS}

\section{Surgical Procedure}

Eight mixed Yorkshire and Danish Landrace pigs with a body weight of $80 \mathrm{~kg}$ were used in this acute experiment. All animals were bred under 


$$
\begin{array}{ll}
\text { Abbreviations and Acronyms } \\
\text { AHCWR = } & \text { annular height to commissural width } \\
& \text { ratio } \\
\mathrm{APM}= & \text { anterior papillary muscle } \\
\mathrm{dl}_{\mathrm{LV}} / \mathrm{dt}= & \text { rate of change in the left ventricular } \\
& \text { long-axis length } \\
\mathrm{ECG}= & \text { electrocardiogram } \\
\mathrm{F}_{\mathrm{APM}}= & \text { force in anterior papillary muscle } \\
\mathrm{F}_{\mathrm{C}} & =\text { closing force } \\
\mathrm{F}_{\mathrm{LV}} & \text { potential valvular-ventricular } \\
& \text { interaction force } \\
\mathrm{F}_{\mathrm{PM}}= & \text { total papillary muscle force } \\
\mathrm{F}_{\mathrm{PPM}}= & \text { force in posterior papillary muscle } \\
\mathrm{l}_{\mathrm{LV}} & =\text { left ventricular long-axis length } \\
\mathrm{LV} & =\text { left ventricular } \\
\mathrm{LVP} & =\text { left ventricular pressure } \\
\mathrm{MV} & =\text { mitral valve } \\
\mathrm{PM} & =\text { papillary muscle } \\
\mathrm{PPM} & =\text { posterior papillary muscle }
\end{array}
$$

standard laboratory conditions, and the experiment complied with the guidelines from the Danish Inspectorate of Animal Experimentation, which also approved the current study. Animals were sedated with an intramuscular injection of midazolam $(0.5 \mathrm{mg} / \mathrm{kg})$ before transport to the laboratory. On arrival, the animals received $30 \mathrm{mg}$ intravenous etomidate and were then intubated and coupled to a ventilator. Continuous analgesia was maintained during the experiment with intravenous fentanyl $(10 \mu \mathrm{g} /$ $\mathrm{kg}$ per hour) and propofol (4 $\mathrm{mg} / \mathrm{kg}$ per hour). Muscle relaxation was obtained by infusion of $12 \mathrm{mg}$ rocuronium hourly. The pigs were euthanized with an injection of $50 \mathrm{~mL} 20 \%$ pentobarbital directly into the left ventricle at the end of each experiment. Details of the animal model have been described previously. 8,9

After establishment of cardiopulmonary bypass and cardiac arrest, the MV was exposed through a left atriotomy and a small incision was made in the apex of the heart. Before closure of the cardiac cavities, microtip pressure catheters were placed in the left ventricle and left atrium to monitor LV and left atrial pressure.

Sonomicrometry. To assess intracardiac geometry, 5 sonomicrometry crystals were placed in the subvalvular apparatus and 8 sonomicrometry crystals (Sonometrics Corporation, London, Ontario, Canada) were placed equally spaced around the mitral annulus (Figure 1). This procedure and use of sonomicrometry has been described previously in detail by our group. $^{10,11}$

Force transducer. One dedicated PM force transducer was implanted in between each dissected PM tip and the remaining body of each PM. Designed with minimal interference of the functionality and competence of the MV and PMs in mind, the short active transducer height of $2 \mathrm{~mm}$ permitted implantation while keeping the MV competent and allowing the PM to contract (Figure 1). Further details on the technical aspects and specifications of the force transducer have been published previously by Askov and colleagues. ${ }^{12}$

\section{Experimental Protocol}

After weaning from cardiopulmonary bypass, the animals were investigated with their chest open. During baseline recording electrocardiogram (ECG), sonomicrometry crystal distances, PM forces, along with LV and left atrial pressure and flow were recorded. To investigate the effect of
LV preload on PM forces, data were also acquired during caval vein occlusion.

\section{Data Acquisition}

Hemodynamics. After the surgical procedure and before measurements were taken, proper leaflet coaptation was confirmed using 2-dimensional ultrasound, and valve competence was confirmed by color Doppler ultrasound (Vivid 7; GE Healthcare Europe GmbH, Brøndby, Denmark).

The PM force transducers were coupled to half-bridge completion strain gauge modules (cDAQ-9172 and NI-9237; National Instruments, Austin, Tex).

LV and left atrial pressure were acquired with microtip pressure catheters (SPC-350MR; Millar Instruments, Houston, Tex), and cardiac output was acquired with a transit time ultrasound perivascular flow probe around the pulmonary artery using a CardioMed data acquisition system (model 4008; CardioMed A/S, Oslo, Norway).

During data acquisition, PM force in the anterior papillary muscle $\left(\mathrm{F}_{\mathrm{APM}}\right)$ and $\mathrm{PM}$ force in the posterior papillary muscle $\left(\mathrm{F}_{\mathrm{PPM}}\right)$ were acquired using the dedicated force transducers along with simultaneous recording of ECG as well as LV and left atrial pressure signals. All signals were acquired using custom-made LabVIEW-based software and hardware for subsequent offline analysis (LabVIEW 2009; National Instruments, Austin, Tex).

The sonomicrometry crystals were connected to an external ultrasound transceiver unit and a dedicated sonomicrometry acquisition system (Sonometrics Corporation, London, Ontario, Canada).

\section{Data Analysis}

Hemodynamics. All data were postprocessed, analyzed offline, and reported as a 10-heart cycle ensemble average, with 1 heart cycle defined as time from QRS peak to peak. The ECG signal was used to synchronize geometry and force data. For statistical analysis, all parameters were reported at early systole, mid systole, end systole, and mid diastole, and at the time of peak PM force. Early systole was defined as $\mathrm{LV}^{\mathrm{dp}} / \mathrm{dt}$ max and end systole was defined as $\mathrm{LV}^{\mathrm{dp}} / \mathrm{dt}$ min. Mid systole and mid diastole was defined as time center points between $\mathrm{LV}^{\mathrm{dp}} / \mathrm{dt}$ max and $\mathrm{LV}^{\mathrm{dp}} / \mathrm{dt}$ min. Cardiac output was calculated by integrating the flow curve during 1 heart cycle.

Forces. A linear regression analysis of peak force and corresponding transmitral pressure during vena cava occlusion was carried out and, based on this relationship, $\mathrm{F}_{\mathrm{APM}}$ and $\mathrm{F}_{\mathrm{PPM}}$ forces were normalized to a peak transmitral pressure of $90 \mathrm{~mm} \mathrm{Hg} .{ }^{13}$ This normalization was performed because the transmitral pressure difference has a direct impact on the PM force.

To account for the magnitude of the PM forces, $\mathrm{F}_{\mathrm{APM}}$ and $\mathrm{F}_{\mathrm{PPM}}$ forces were added and described as the total papillary muscle force $\left(\mathrm{F}_{\mathrm{PM}}\right.$; Figure 2). In this force equilibrium, it was assumed that the apically directed $\mathrm{F}_{\mathrm{PM}}$ was counterbalanced by (1) an equal and oppositely directed force comprising a closing force $\left(\mathrm{F}_{\mathrm{C}}\right)$ created by the LVP acting on the MV leaflets and (2) a potential valvular-ventricular interaction force $\left(\mathrm{F}_{\mathrm{LV}}\right)$ in the longitudinal direction transmitted through the PM and chordal complex to the LV wall, according to

$$
F_{P M} \approx F_{C}+F_{L V}
$$

$\mathrm{F}_{\mathrm{LV}}$ tended to shorten the LV longitudinal axis and to promote LV ejection. It was assumed that the MV was closing during early systole, and only closed fully from the time of peak PM force and during the remainder of systole; thus, $\mathrm{F}_{\mathrm{C}}$ was assumed to be 0 at early systole and increasing until complete valve closure at the time of peak PM force. Furthermore, $\mathrm{F}_{\mathrm{C}}$ was also set to 0 during diastole because the $\mathrm{MV}$ was open during this period. To estimate the opposing force acting on the MV leaflets, $\mathrm{F}_{\mathrm{C}}$ was calculated as the transmitral pressure multiplied by the planar mitral annular orifice area. This force was also normalized to a peak transmitral pressure difference of $90 \mathrm{~mm} \mathrm{Hg}$ to compare it with the normalized PM forces. 

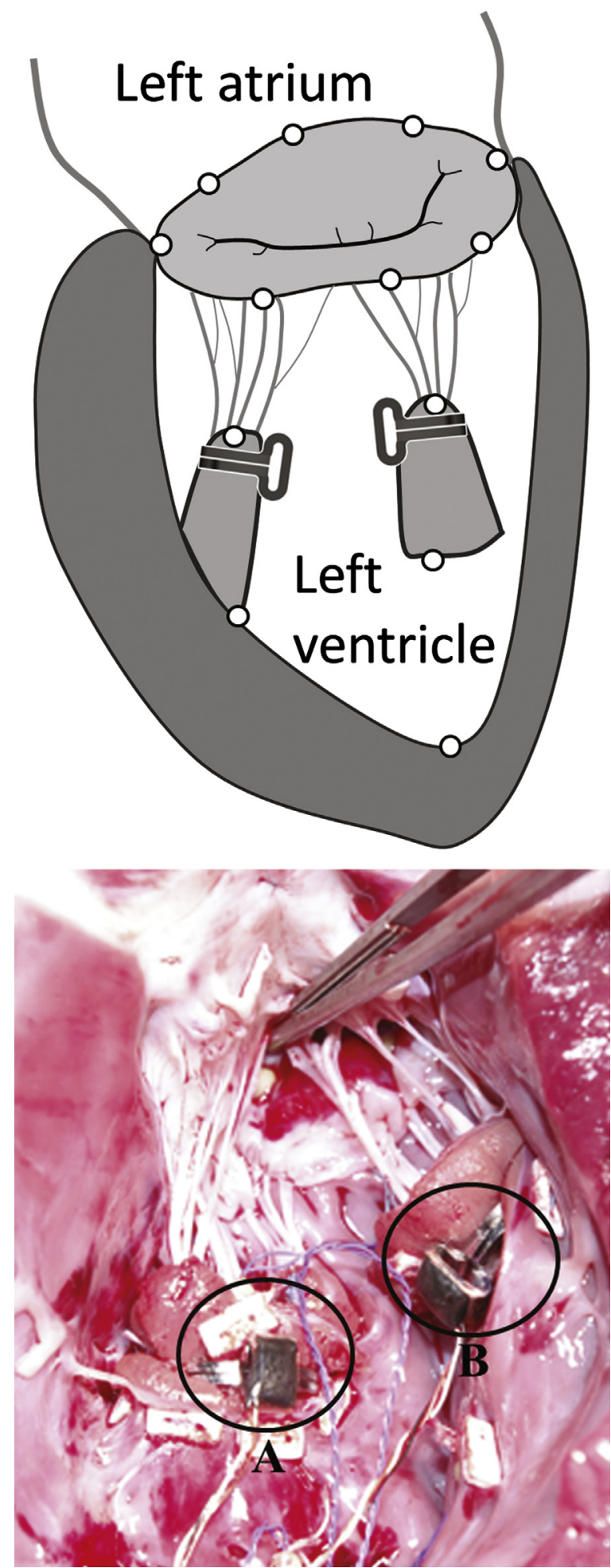

FIGURE 1. Top, Thirteen sonomicrometry crystals were placed in the left ventricle and spaced equally around the mitral annulus to monitor left ventricular and mitral valve geometry. Dedicated force transducers for measurements in vivo were implanted on both papillary muscles. Bottom, Explanted heart after animal experiment showing implanted force transducers in the posterior $(A)$ and anterior $(B)$ papillary muscle. Wires are exteriorized out through an incision in the apex.
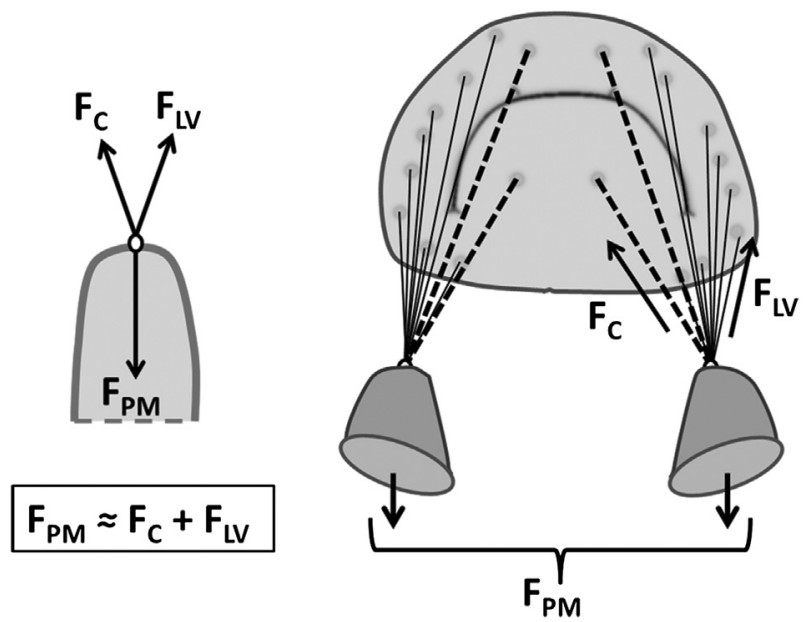

FIGURE 2. Left, Diagram of the force exchange between the papillary muscle tips and the mitral valve, along with the force equilibrium equation. The total papillary muscle force $\left(F_{P M}\right)$ is opposed by the combined force of the chordae tendineae, which is comprised of the closing force $\left(F_{C}\right)$ and a potential valvular-ventricular interaction force $\left(F_{L V}\right)$. Right, Long-axis view of the left ventricle and the mitral valve with attaching strut chords (dashes) and basal chords (lines) comprising the continuity between the mitral valve and the papillary muscles. Marginal chordae tendineae are not shown.

Sonomicrometry. After postprocessing the sonomicrometry data, multidimensional scaling techniques (CardioSoft and SonoXYZ; Sonometrics Corporation, London, Ontario, Canada) were used to construct a 3-dimensional coordinate system and to assess LV and mitral annular geometries. ${ }^{14}$ As a measure of the temporal change in the LV long-axis length $\left(l_{\mathrm{LV}}\right)$ the average distance from the 2 crystals placed at the annular fibrous trigones to the crystal placed in the LV apex was calculated, and the rate of change in the $\mathrm{LV}$ long-axis length $\left(\mathrm{dl}_{\mathrm{LV}} / \mathrm{dt}\right)$ was derived. Two data sets had to be excluded because of flawed signals calculating $1_{\mathrm{LV}}$ and $\mathrm{dl}_{\mathrm{LV}} / \mathrm{dt}$; thus, group means of $\mathrm{l}_{\mathrm{LV}}$ and $\mathrm{d} \mathrm{l}_{\mathrm{LV}} / \mathrm{dt}$ are based on 6 data sets.

A least square fit plane was constructed based on the coordinates from the 8 mitral annular crystals. The annular height was defined as the sum of the distances from the center of the trigones to the least square fit plane plus the average distance from the commissural crystals to the least square fit plane. ${ }^{10,11,15}$ Based on the annular height and the distance between the crystals placed at each commissure, the annular height to commissural width ratio (AHCWR) was calculated. ${ }^{15}$ Mitral annular area was calculated as the planar orifice area assessed by projecting the positions of the annular crystals onto the least square fit plane and then calculating the area by dividing it into 6 triangles.

\section{Statistic Analysis}

All data are reported as mean \pm 1 standard error of the mean. For every animal, each reported parameter represents the mean of 10 consecutive heart cycles. The change in each parameter throughout this heart cycle was analyzed using repeated-measures 1-way analysis of variance, with $P<.05$ considered statistically significant (GraphPad Prism 5; GraphPad Software, Inc, La Jolla, Calif). Normality of the tested data was verified with the D'Agostino-Pearson normality test.

\section{RESULTS}

Average crossclamp time was $103 \pm 2$ min and the average pump time was $178 \pm 17$ min. Mean steady-state heart rate was $108 \pm 7 \mathrm{bpm}$, mean peak LVP was $69.8 \pm 4.5 \mathrm{~mm}$ 
$\mathrm{Hg}$, and mean cardiac output was $3.9 \pm 0.2 \mathrm{~L} / \mathrm{min}$. MV competence was verified in all 8 animals using color Doppler ultrasound. All force and geometry measurements are summarized in Table 1.

PM forces increased rapidly during early systole and peaked between early and mid systole. The initial shoulder of the PM force tracings was followed by a plateau between mid and end systole, and then a rapid decline in force during end systole/early diastole. In general, $\mathrm{F}_{\mathrm{APM}}$ and $\mathrm{F}_{\mathrm{PPM}}$ peaked shortly before mid systole, and although PM forces followed the shape of the LVP, a delay between change in LVP and change in PM force was observed. There was a close linear relationship between peak force and corresponding transmitral pressure difference during vena cava occlusion, with an $r^{2}$ value of approximately 0.91 and 0.89 for $\mathrm{F}_{\mathrm{APM}}$ and $\mathrm{F}_{\mathrm{PPM}}$, respectively. Normalized peak $\mathrm{F}_{\mathrm{APM}}$ and $\mathrm{F}_{\mathrm{PPM}}$ was $5.9 \pm 0.6 \mathrm{~N}$ and $5.8 \pm 0.7 \mathrm{~N}$, respectively, and no statistically significant difference was detected between normalized peak $\mathrm{F}_{\mathrm{APM}}$ and $\mathrm{F}_{\mathrm{PPM}}(P>.05$ by unpaired Student $t$ test), although they could differ during individual experiments (Figure 3).

Based on the equation $\mathrm{F}_{\mathrm{PM}} \approx \mathrm{F}_{\mathrm{C}}+\mathrm{F}_{\mathrm{LV}}, \mathrm{F}_{\mathrm{LV}}$ was extracted, and the normalized group mean of $\mathrm{F}_{\mathrm{PM}}, \mathrm{F}_{\mathrm{C}}$, and $F_{L V}$ during 1 heart cycle was calculated (Figure 4). Estimated $F_{C}$ peaked in mid systole, coinciding with peak LVP, and decreased during the remainder of the ejection phase. Accordingly, at time of peak $\mathrm{F}_{\mathrm{PM}}, \mathrm{F}_{\mathrm{C}}$ could only account for approximately half of $\mathrm{F}_{\mathrm{PM}}$, and $\mathrm{F}_{\mathrm{C}}$ was lower than $\mathrm{F}_{\mathrm{PM}}$ in the remaining part of systole. The potential valvularventricular force transfer as described by $F_{L V}$ was present from the time of MV closure at early systole, and increased to a maximum value of $5.7 \pm 0.6 \mathrm{~N}$ at end systole.

The dynamic changes of $l_{\mathrm{LV}}$ and annular shape change followed a synchronous pattern. $1_{\mathrm{LV}}$ decreased throughout the LV ejection phase to a minimum value at end systole and increased during diastole, and LV filling reached a maximum value at the onset of LV systole (Figure 3). During the initial phase of systole, the LV long axis elongated rapidly, and from early systole until time of peak force it reached its maximum rate of shortening as described by $\mathrm{dl}_{\mathrm{LV}} / \mathrm{dt}$ (Table 1 ). Peak $F_{P M}$ coincided with the peak rate of $L V$ long-axis shortening. There was a linear correlation between $l_{\mathrm{LV}}$ and $\mathrm{F}_{\mathrm{LV}}$ during caval occlusion in all animals (Figure E1).

The AHCWR exhibited a similar course, with maximal annular flattening at the onset of systole and maximum saddle shape (maximum AHCWR) at end systole before LV relaxation. Mitral annular area changed significantly throughout the heart cycle and decreased during systole (Figure 3).

\section{DISCUSSION}

In 1956, Rushmer ${ }^{16}$ was the first to suggest a role for the MV subvalvular apparatus in maintaining a synchronous and efficient LV contraction pattern. Later, several experimental studies demonstrated that the PM-chordal complex serve primarily as mechanical connections between the LV apex and base during ejection. ${ }^{7,17}$ Lillehei and colleagues ${ }^{18}$ applied these theories to the clinical problem of postoperative low cardiac output after MV replacement, and since then clinical studies have confirmed the beneficial role of the mitral subvalvular apparatus for LV function.

Our study is the first to assess the magnitude and time course of the force transfer between the MV apparatus and LV wall complex in vivo. Integrative assessment of both PM tip forces as well as valvular and subvalvular geometries allowed a thorough investigation of the role of the force exchange at the PM tips and how it relates to the force balance of the LV.

The current study demonstrated a significant force transfer in addition to $\mathrm{F}_{\mathrm{C}}$ acting on the MV leaflets. This longitudinal force is transmitted through the PM-chordal complex to the LV wall during ejection and hereby constitutes an essential component of valvular-ventricular interaction to enhance LV systolic pump performance. Furthermore, peak LV long-axis rate of shortening coincided with peak $\mathrm{F}_{\mathrm{PM}}$. The magnitude and temporal change

TABLE 1. Force and geometric parameters

\begin{tabular}{|c|c|c|c|c|c|c|}
\hline Parameter & Early systole & Peak force & Mid systole & End systole & Mid diastole & $P$ value \\
\hline $\mathrm{F}_{\mathrm{APM}}, \mathrm{N}$ & $1.40 \pm 0.3$ & $5.90 \pm 0.60$ & $5.60 \pm 0.6$ & $3.90 \pm 0.5$ & $0.20 \pm 0.1$ & .0001 \\
\hline $\mathrm{F}_{\mathrm{PPM}}, \mathrm{N}$ & $1.50 \pm 0.4$ & $5.80 \pm 0.70$ & $5.30 \pm 0.7$ & $3.30 \pm 0.4$ & $0.30 \pm 0.1$ & .0001 \\
\hline $\mathrm{F}_{\mathrm{PM}}, \mathrm{N}$ & $2.90 \pm 0.7$ & $11.70 \pm 0.80$ & $10.90 \pm 0.8$ & $7.20 \pm 0.7$ & $0.50 \pm 0.1$ & .0001 \\
\hline $\mathrm{F}_{\mathrm{C}}, \mathrm{N}$ & $0.00 \pm 0.0$ & $6.80 \pm 0.30$ & $7.00 \pm 0.7$ & $1.60 \pm 0.2$ & $0.00 \pm 0.0$ & .0001 \\
\hline $\mathrm{F}_{\mathrm{LV}}, \mathrm{N}$ & $2.90 \pm 0.7$ & $4.80 \pm 0.70$ & $3.90 \pm 0.7$ & $5.70 \pm 0.6$ & $0.50 \pm 0.1$ & .0037 \\
\hline $1_{\mathrm{LV}}, \mathrm{mm}$ & $91.40 \pm 1.3$ & $89.30 \pm 0.90$ & $88.2 \pm 0.7$ & $85.3 \pm 1.2$ & $88.3 \pm 1.1$ & .0001 \\
\hline $\mathrm{dl}_{\mathrm{LV}} / \mathrm{dt}, \mathrm{mm} / \mathrm{s}$ & $555.00 \pm 281$ & $-1551 \pm 272$ & $-1519 \pm 270$ & $-549 \pm 149$ & $855 \pm 340$ & .0001 \\
\hline $\mathrm{M}_{\mathrm{AA}}, \mathrm{mm}^{2}$ & $653.00 \pm 21$ & $599 \pm 28$ & $596 \pm 27$ & $591 \pm 27$ & $698 \pm 30$ & .0001 \\
\hline AHCWR, \% & $9.60 \pm 2.0$ & $10.6 \pm 2.0$ & $11.0 \pm 1.8$ & $11.7 \pm 1.9$ & $10.4 \pm 2.2$ & .3241 \\
\hline
\end{tabular}

Measured and calculated parameters throughout 1 heart cycle along with $P$ values indicating statistically significant variance between time points (1-way analysis of variance). All data are reported as mean \pm 1 standard error of the mean. $F_{A P M}$, Force in anterior papillary muscle; $F_{P P M}$, force in posterior papillary muscle; $F_{P M}$, total papillary muscle force; $F_{C}$, closing force; $F_{L V}$, potential valvular-ventricular interaction force; $l_{L V}$, left ventricular long-axis length; $d l_{L V} / d t$, rate of change in the left ventricular long-axis length; $M_{A A}$, mitral annular area; $A H C W R$, annular height to commissural width ratio. 

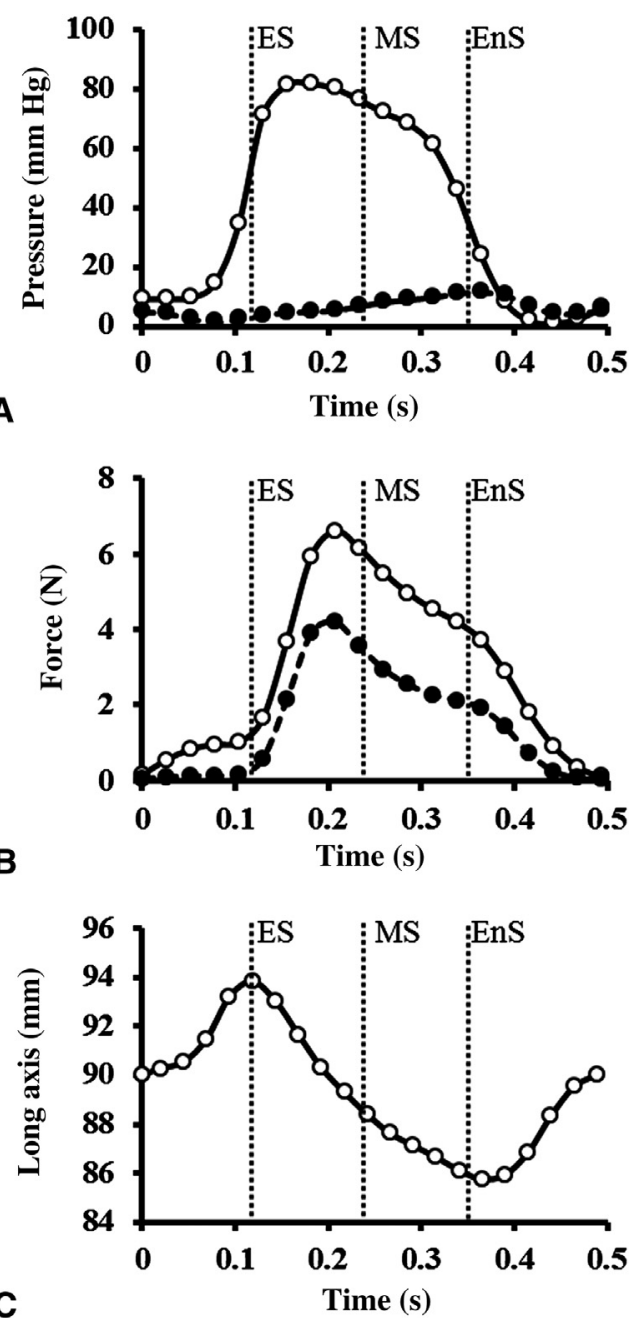

C
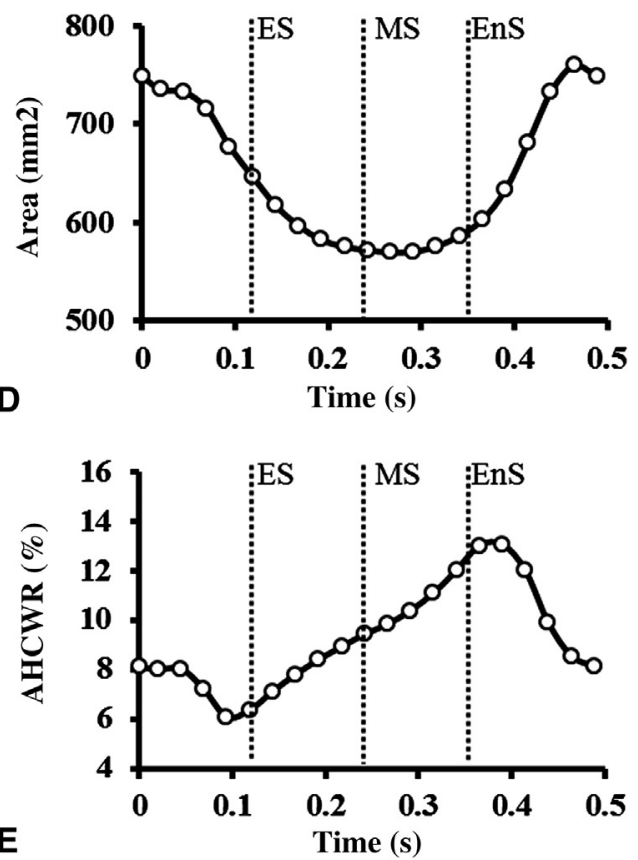

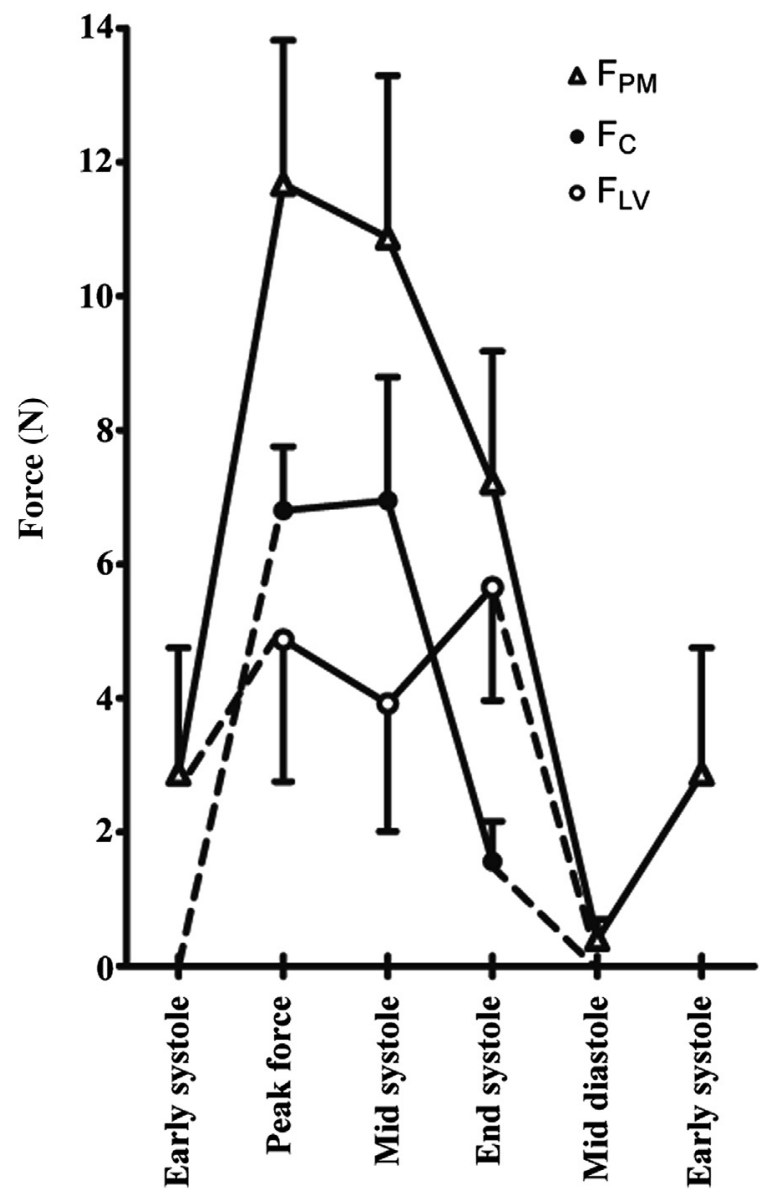

FIGURE 4. Group mean of total papillary muscle force $\left(F_{P M}\right.$, white triangles), closing force $\left(F_{C}\right.$, solid black circles $)$, and the potential valvularventricular interaction force $\left(F_{L V}\right.$, open circles $)$ at 5 time points normalized to a transmitral pressure of $90 \mathrm{~mm} \mathrm{Hg}$. Dashed line indicates time intervals when the mitral valve is either closing or opening.

of the PM tip force, therefore, reflect the complex mechanical coupling between the MV and the LV wall, which is mediated through the PMs and the chordae, emphasizing the crucial role of preserving MV-LV continuity during MV surgery.

The peak $\mathrm{F}_{\mathrm{PM}}$ measured was $5.90 \pm 0.62 \mathrm{~N}$ for the APM and $5.77 \pm 0.72 \mathrm{~N}$ for the PPM at a transmitral pressure of $90 \mathrm{~mm} \mathrm{Hg}$. Taking the magnitude of the transmitral pressure into account, the measured $\mathrm{F}_{\mathrm{PM}} \mathrm{S}$ in this study

FIGURE 3. Example of simultaneous force and geometry measurements from 1 experiment as an ensemble average of 10 heart cycles. A, Left ventricular pressure (open circles) and left atrial pressure (closed circles). $\mathrm{B}$, Anterior papillary muscle force (open circles) and posterior papillary muscle force (closed circles). C, Left ventricular long-axis dimension. D, Mitral annular area. E, Annular height to commissural width ratio. ES, Early systole; $M S$, mid systole; EnS, end systole; $A H C W R$, annular height to commissural width ratio. 
are higher than what has been simulated or calculated in earlier studies. In 1965, Burch and associates ${ }^{19}$ calculated the force supported by each PM based on the transmitral pressure during systole to be approximately $1.82 \mathrm{~N}$. Later, Jensen and coworkers ${ }^{20}$ simulated $F_{P M}$ in a pulsatile in vitro model mounted with native MVs and found that each $\mathrm{F}_{\mathrm{PM}}$ was $4.1 \pm 0.9 \mathrm{~N}$ at a transmitral pressure of 120 $\mathrm{mm} \mathrm{Hg}$, which was the same magnitude as the $\mathrm{F}_{\mathrm{C}}$ calculated in that same study. Although simulation of the LV myocardium and the potential force transfer between the LV wall through the chordae to the MV was not feasible in this in vitro setup, their study gave a precise estimate of the pressure-induced $\mathrm{F}_{\mathrm{C}}$ acting on the MV leaflets in the same range as estimated in our study. $\mathrm{F}_{\mathrm{C}}$ was $6.8 \pm$ $0.3 \mathrm{~N}$ when $\mathrm{F}_{\mathrm{PM}}$ peaked at $11.7 \pm 0.8 \mathrm{~N}$, showing that the PMs exert a considerably greater force than the force needed to counterbalance $F_{C}$ to prevent $M V$ prolapse. One may wonder how higher forces can be transferred at the PM tip than the calculated $\mathrm{F}_{\mathrm{C}}$ acting on the leaflets without causing the mitral leaflets to open. The explanation must be that the PMs are anchored to the MV annulus both through secondary and basal chordae. The secondary chordae insert into the central portion of the leaflets and the basal chordae insert into the base of the leaflets around approximately two thirds of the annular periphery (Figure 2). ${ }^{21}$ We have shown previously ${ }^{13}$ that the secondary (strut) chordae are the major load-bearing chordae and they carry significantly higher load than the marginal chordae. Jimenez and colleauges ${ }^{22}$ showed in an in vitro study that the basal chordae also carried a significant load of $\geq$ two thirds of the load of a strut chordae. Furthermore, $\mathrm{He}$ and associates ${ }^{21}$ demonstrated in a static in vitro model that the basal chordae are able to transfer force directly between the PM and the base of the MV independent of the strut and marginal chords. Accordingly, a significant load can be transferred through the basal chordae and distributed toward the mitral annulus without pulling the leaflets apart in an apical direction. During mitral annuloplasty ring implantation, the basal chordae of the commissures have also been found to be responsible for large strains in flat annuloplasty rings in this area, which substantiates that considerable forces are transferred through these chordae. ${ }^{10}$ The role of the strut chordae in mediating valvular-ventricular interaction have also been emphasized in several experimental studies, ${ }^{23,24}$ which showed that cutting strut chordae altered LV geometry, remodeled the myocardium between the PMs, and caused global and regional systolic dysfunction. We have shown previously ${ }^{5}$ in pigs that strut chordal preservation was equivalent to total valve preservation during MV replacement, whereas total chordal resection caused significant LV slimming with compensatory increases in fractional shortening, thus emphasizing the role of the PM-chordal continuity for longitudinal LV mechanics during ejection.
Although peak PM tip forces and the transmitral pressure difference were correlated closely (Figure E1), a temporal delay between LV pressure and PM tip force was observed. This time delay might have been caused by temporal changes in the subvalvular geometry combined with the temporal changes in mitral annular area. Using tantalum myocardial markers placed on the tip and base of the PMs, Rayhill and coworkers ${ }^{25}$ conducted a study on dogs showing the PMs shortened during ejection and lengthened during diastole, and thereby maintained an almost constant distance from the PM tip to the mitral annulus plane in systole. The PM lengths changed minimally during the isovolumic periods. Thus, the temporal delay between the increase in LVP and the increase in PM tip force could simply be explained by the fact that LV long-axis and PM shortening occur during ejection, but after the onset of an LVP increase during isovolumic contraction. Furthermore, the force transmission at the PM tip requires an equal and counter-directed $F_{C}$, which is driven principally by a transmitral pressure difference acting on MV leaflets in the closed position. Hence, the momentum of leaflet motion during MV closure may also contribute to the observed temporal delay in force generation at the PM tips. Last, compared with previous chordal force measurements, ${ }^{13}$ PM tip forces represent a more compound and elastic system than a single chorda alone, which results in a less stiff and direct transfer of forces, and possibly a temporal delay, as observed (Figure 3).

The shape of the MV annulus conformed from a flat configuration in diastole (AHCWR $=7.7 \pm 2.0 \%$ ) to a maximum saddle shape at end systole (AHCWR $=13.3 \pm$ $1.5 \%$ ), and this observation was in accordance with other experimental data. ${ }^{10,11,15}$ Considering the magnitude of forces transferred from the PM tips to the MV leaflets and annular insertion sites, it is appealing to assume that the systolic saddle shape of the mitral annulus is facilitated by forces transferred through the basal/commissural chordae to the mitral annulus. Accordingly, AHCWR also changed considerable during early systole and during the time interval of peak PM tip force, and the rapid decrease in AHCWR at LV relaxation was associated with a parallel decrease in PM tip force. However, because peak PM tip force and maximum AHCWR did not coincide, the mitral annulus shape change in systole should be considered a consequence of regional $\mathrm{LV}$ myocardial deformation during ejection, during which force transfer through the PM-chordal complex to the mitral annulus may contribute.

In conclusion, this study showed that PM tip forces are significantly greater than the LVP forces acting on the MV leaflets, which suggests a considerable residual force transfer through the PM-chordal complex to the LV wall, aiding in LV longitudinal shortening and ejection. We speculate that this mechanical coupling is likely to be transferred from the PM tips to the mitral annulus through 
chordae inserting adjacent to the mitral annulus, allowing a considerable and additional force transfer, while the MV leaflets maintain their closed position. The magnitude of the total PM tip force-almost 2 times $>\mathrm{F}_{\mathrm{C}}$-displays the negligence of not preserving MV-LV continuity in MV surgery whenever possible.

\section{Limitations}

Important limitations exist that must be taken into account. First, the measurements in this study were performed in an acute setting with open chest and in healthy hearts after cardiopulmonary bypass and invasive surgery, which naturally may have impacted the LV myocardial function and thus the ventricular-valvular interaction. Ideally, this study should be carried out in a chronic setting in which the animal is allowed to recover fully before measurements are taken. However, because of the frailty of the porcine model and limitations of the force transducer durability, this was not feasible.

$\mathrm{F}_{\mathrm{C}}$ calculated in this study represented only a rough estimate of the total force acting on the mitral valve orifice area in systole and may not take into account regional deformation of the mitral annulus and leaflet tissue, as well as the influence of flow characteristics, Venturi effects, and so forth.

We thank Dorte Larsen, Tanja Thomsen, Rasmus Soerensen, Felix Metzner, Jacob Oest, Leo Madsen, Pernille Jakobsen, Edit Rebbe, Klavs Ebbensgaard, Pia Sprogoe, and Peter Nielsen for assistance during surgery.

\section{References}

1. Sarris GE, Miller DC. Valvular-ventricular interaction: the importance of the mitral chordae tendineae in terms of global left ventricular systolic function. J Card Surg. 1988;3:215-34

2. Hansen DE, Cahill PD, DeCampli WM, Harrison DC, Derby GC, Mitchell RS, et al. Valvular-ventricular interaction: importance of the mitral apparatus in canine left ventricular systolic performance. Circulation. 1986;73:1310-20.

3. Yun KL, Fann JI, Rayhill SC, Nasserbakht F, Derby GC, Handen CE, et al. Importance of the mitral subvalvular apparatus for left ventricular segmental systolic mechanics. Circulation. 1990;82:IV89-104.

4. Moon MR, DeAnda A Jr, Daughters GT, Ingels NB Jr, Miller DC. Effects of mitral valve replacement on regional left ventricular systolic strain. Ann Thorac Surg. 1999;68:894-902.

5. Smerup M, Funder J, Nyboe C, Hoyer C, Pedersen TF, Ribe L, et al. Strut chordal-sparing mitral valve replacement preserves long-term left ventricular shape and function in pigs. J Thorac Cardiovasc Surg. 2005;130:1675-82.

6. Dagum P, Timek TA, Green GR, Lai D, Daughters GT, Liang DH, et al. Coordinate-free analysis of mitral valve dynamics in normal and ischemic hearts. Circulation. 2000;102:III62-9.
7. Joudinaud TM, Kegel CL, Flecher EM, Weber PA, Lansac E, Hvass U, et al. The papillary muscles as shock absorbers of the mitral valve complex: an experimental study. Eur J Cardiothorac Surg. 2007;32:96-101.

8. Nielsen SL, Lomholt M, Johansen P, Hansen SB, Andersen NT, Hasenkam JM. Mitral ring annuloplasty relieves tension of the secondary but not primary chordae tendineae in the anterior mitral leaflet. J Thorac Cardiovasc Surg. 2011;141: 732-7.

9. Nielsen SL, Hansen SB, Nielsen KO, Nygaard H, Paulsen PK, Hasenkam JM. Imbalanced chordal force distribution causes acute ischemic mitral regurgitation mechanistic insights from chordae tendineae force measurements in pigs. J Thorac Cardiovasc Surg. 2005;129:525-31.

10. Jensen MO, Jensen H, Smerup M, Levine RA, Yoganathan AP, Nygaard H, et al. Saddle-shaped mitral valve annuloplasty rings experience lower forces compared with flat rings. Circulation. 2008;118:S250-5.

11. Jensen MO, Jensen H, Nielsen SL, Smerup M, Johansen P, Yoganathan AP, et al What forces act on a flat rigid mitral annuloplasty ring? J Heart Valve Dis. 2008; 17:267-75.

12. Askov JB, Honge J, Nygaard H, Hasenkam J, Nielsen S, Jensen M. Papillary muscle force transducer for measurement in vivo. Cardiovasc Eng Technol. 2011;2:1-7.

13. Lomholt M, Nielsen SL, Hansen SB, Andersen NT, Hasenkam JM. Differential tension between secondary and primary mitral chordae in an acute in-vivo porcine model. J Heart Valve Dis. 2002;11:337-45.

14. Gorman JH III, Gupta KB, Streicher JT, Gorman RC, Jackson BM, Ratcliffe MB et al. Dynamic three-dimensional imaging of the mitral valve and left ventricle by rapid sonomicrometry array localization. J Thorac Cardiovasc Surg. 1996;112: 712-26.

15. Timek TA, Glasson JR, Lai DT, Liang D, Daughters GT, Ingels NB Jr, et al. Annular height-to-commissural width ratio of annulolasty rings in vivo. Circulation. 2005;112:I423-8.

16. Rushmer RF. Initial phase of ventricular systole: asynchronous contraction. Am J Physiol. 1956;184:188-94.

17. Tsakiris AG, Rastelli GC, Amorim DS, Titus JL, Wood EH. Effect of experimental papillary muscle damage on mitral valve closure in intact anesthetized dogs. Mayo Clin Proc. 1970;45:275-85.

18. Lillehei CW, Levy MJ, Bonnabeau RC Jr. Mitral valve replacement with preservation of papillary muscles and chordae tendineae. J Thorac Cardiovasc Surg 1964;47:532-43.

19. Burch GE, DePasquale NP. Time course of tension in papillary muscles of heart: theoretical considerations. JAMA. 1965;192:701-4.

20. Jensen MO, Fontaine AA, Yoganathan AP. Improved in vitro quantification of the force exerted by the papillary muscle on the left ventricular wall: threedimensional force vector measurement system. Ann Biomed Eng. 2001;29: 406-13.

21. He S, Weston MW, Lemmon J, Jensen M, Levine RA, Yoganathan AP. Geometric distribution of chordae tendineae: an important anatomic feature in mitral valve function. J Heart Valve Dis. 2000;9:495-501.

22. Jimenez JH, Soerensen DD, He Z, Ritchie J, Yoganathan AP. Mitral valve function and chordal force distribution using a flexible annulus model: an in vitro study. Ann Biomed Eng. 2005;33:557-66.

23. Nielsen SL, Timek TA, Green GR, Dagum P, Daughters GT, Hasenkam JM, et al Influence of anterior mitral leaflet second-order chordae tendineae on left ventricular systolic function. Circulation. 2003;108:486-91.

24. Rodriguez F, Langer F, Harrington KB, Tibayan FA, Zasio MK, Cheng A, et al Importance of mitral valve second-order chordae for left ventricular geometry, wall thickening mechanics, and global systolic function. Circulation. 2004; 110:II115-22.

25. Rayhill SC, Daughters GT, Castro LJ, Niczyporuk MA, Moon MR, Ingels NB Jr, et al. Dynamics of normal and ischemic canine papillary muscles. Circ Res. 1994; 74:1179-87. 

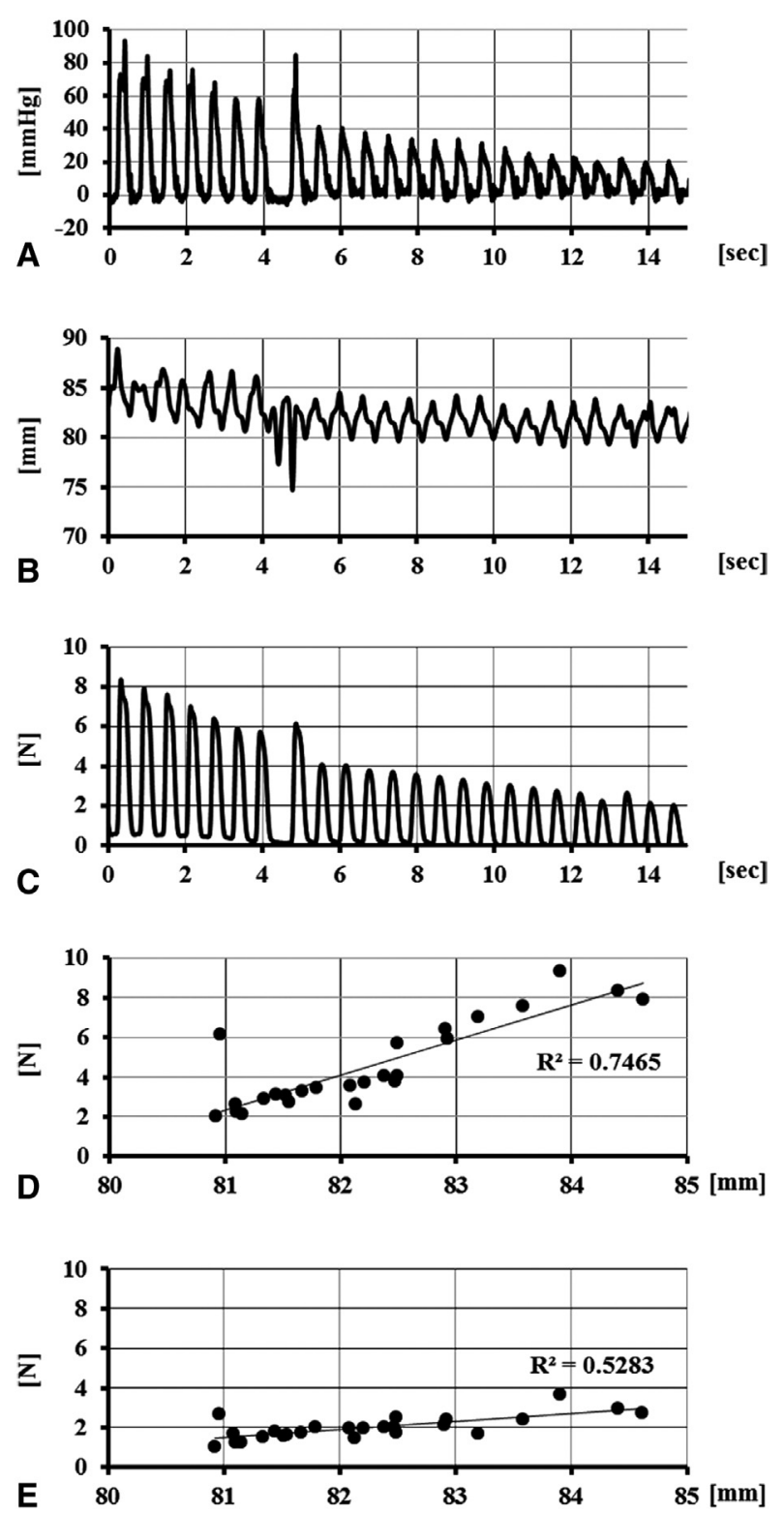

FIGURE E1. Example of observed change in geometry and forces during a caval occlusion from one experiment as well as the correlation between change in forces and geometry during that same caval occlusion. A, Transmitral pressure. B, Left ventricular long-axis length $\left(l_{L V}\right)$. C, Total papillary muscle force $(F P M)$. D, Correlation between peak FPM and $\mathrm{l}_{\mathrm{LV}}$. E, Correlation between peak potential valvular-ventricular interaction force transmitted to the left myocardial wall $\left(F_{L V}\right)$ and $\mathrm{l}_{\mathrm{LV}}$. 